\title{
Viñetas hechizadas. Los cómics de la occulture
}

\section{Bewitched comic strips. The occulture comic-books}

\author{
Roger Ferrer Ventosa \\ Universidad de Lisboa
}

Doctor en humanidades por la Universitat de Girona (2018), con una tesis en la que estudió las relaciones entre el pensamiento mágico-simbólico y el arte. Investigador post doctoral en la Universidad de Lisboa. Especializado en analizar las características poseídas por las imágenes para difundir ideas con una gran eficacia comunicativa, en un estudio transdisciplinar que une la estética con la antropología, la filosofía y los estudios culturales y religiosos. Además, también ha publicado artículos sobre el cine en su aspecto metafórico como plasmador de ideas, sobre todo en el cine fantástico.

Fecha de recepción: 24 de diciembre de 2020

Fecha de aceptación definitiva: 16 de febrero de 2021 


\title{
Resumen
}

Un rasgo en común que comparten alguno de los cómics más importantes desde los años noventa es el peso del ocultismo en ellos. Tanto en The Sandman, como en Los invisibles, Promethea, Strangehaven o Saucer country se hallan rastros notorios de lo que el investigador Christopher Partridge denominó occulture, obras de arte que se sirven del esoterismo. En las siguientes páginas se analizará ese factor en las obras citadas, mostrando la manera en que se aprovechan de temas, así como también sus citas directas a algunos de los principales exponentes del esoterismo.

Palabras clave: Alan Moore, Los invisibles, Occulture, Promethea, The Sandman

\begin{abstract}
Some of the most important comic books from the nineties share a common trait: occultism has a relevant role in them. The scholar Christopher Partridge coined the term occulture to refer to these art works that include references to esotericism. We can observe this in The Sandman, The invisibles, Promethea, Strangehaven or Saucer country. In the following pages, you will find an analysis of the presence of this factor in the works above mentioned. We will show how the authors use these topics. We will also talk about their direct mentions of some of the main exponents of esotericism.
\end{abstract}

Keywords: Alan Moore, The Invisibles, Occulture, Promethea, The Sandman

\section{Cita bibliográfica}

Ferrer Ventosa, R. «Viñetas hechizadas. Los cómics de la occulture», en CuCo, Cuadernos de cómic n. ${ }^{\circ} 16$ (2021), pp. 7-37. 
A los iconos del infinito ofrezco las bandas carmesies de Cyttorak. ${ }^{1}$

\section{Occulture}

Como elemento fundamental para contextualizar los cómics que se comentarán, conviene primero introducir un término que no pertenece exclusivamente a los cómics sino a un marco cultural genérico. En 2004 Christopher Partridge introdujo en el ámbito académico una etiqueta que ha gozado de gran éxito, utilizada por muchos otros investigadores desde entonces; parecería que el concepto flotaba en el aire y solo faltaba acuñarlo con una etiqueta: se trata de occulture, nuevo concepto que pretende definir un fenómeno cultural que, en el sentido dado inicialmente por Partridge, viene sucediendo en las últimas décadas. ${ }^{2}$ Dicho neologismo señala y en cierta medida cartografía un cambio cultural: el de nuevas obras artísticas, tanto pop como underground, que se sirven de la terminología o de las ideas del esoterismo. ${ }^{3}$

Partridge publicó en el año 2004 The Re-Enchantment of the West, un estudio sobre la cultura popular influida, a su juicio, por lo esotérico, con ejemplos que van de Marilyn Manson a Drácula, del techno-trance al dub jamaicano o a la ciencia-ficción. En la investigación presente se empleará occulture en el sentido amplio que le otorga Partridge, con un pie en el esoterismo y el otro en formas de arte de la cultura popular, como fenómeno histórico de las últimas décadas.

De acuerdo con la forma de juzgar el pensamiento mágico y religioso desde el xviII, la cultura europea viviría inmersa en una transformación - entendida como evolución- de desencantamiento del mundo, expresión acuñada por el influyente sociólogo Max Weber. En Sociología de la religión (1920) consideró que la mentalidad empírico-racional había desencadenado dicho proceso. ${ }^{4}$

Que lo religioso retrocedía resultaba aún un motivo recurrente en el mundo académico dominante hasta los años ochenta del siglo pasado. Muchos sociólogos estaban

\footnotetext{
1 Doctor Extraño, Strange Tales n. ${ }^{\circ}$ 156. [Traducción por el autor de este artículo].

2 Partridge, C. The Re-Enchantment of the West. Volume 2. London / New York, T\&T Clark International, 2005, p. 68.

3 En el artículo, se empleará esoterismo y ocultismo como sinónimos.

${ }^{4}$ «A medida que el intelectualismo hace retroceder la fe en la magia y los acontecimientos del mundo pierden su hechizo, pierden su contenido mágico». En Weber, M. Sociología de la religión. Madrid, Itsmo, 1997, p. 178.
} 
persuadidos de que la religión vivía un proceso de disminución de creyentes, así como de poder social. Pero la teoría fuerte de Partridge afirma que lo que ha acabado sucediendo desde las dos últimas décadas del siglo xx, como atestigua la referida occulture, ha sido un pasar a pensar lo contrario, que lo mágico está entrelazado con lo real puesto que lo están lo imaginario y lo simbólico- ${ }^{5}$ Según él, lo que ha sucedido ha sido una especie de corrimiento de tierras, que ha significado la pérdida de poder y autoridad de las iglesias mayoritarias - y no de todas ellas - pero el incremento de seguidores de nuevas formas de espiritualidad no institucionalizada.

Por tanto, más que un desencantamiento del mundo en la hipótesis weberiana, lo que ha acontecido en las últimas décadas ha sido un movimiento hacia formas religiosas fuera de las ortodoxias. Ese movimiento, que toma impulso después de la contracultura, explica el incremento exponencial vivido por el ocultismo en el mismo periodo, en que ha pasado del ostracismo a finales del xvinI, al extremo opuesto en los últimos veinte años: su estudio universitario (por ejemplo, en la Universidad de Ámsterdam, en el grupo dirigido por Wouter Hanegraaff), el continuo éxito de ventas de productos New Age, o su aparición en los grandes medios de comunicación de masas.

Además, esas nuevas espiritualidades se han difundido en múltiples obras culturales de estratos muy diversos: del mainstream a obras underground de culto. Con ello, tenemos la occulture y esa preponderancia central del ocultismo en sus muchas variantes dentro del arte. ${ }^{6}$ Partridge primero le imprimió un sentido estricto, como fenómeno histórico preciso, a raíz del nuevo espíritu de época impulsado por la contracultura y la New Age.

Pensemos, por ejemplo, en el auge del cine o las series de tema fantástico en innumerables blockbusters. Se trata de un sostenido éxito cultural que emplea parafernalia esotérica. En cualquier caso, esos blockbusters de fantástico demuestran la gran transformación operada en el gusto de las masas, no hay más que comparar el número de producciones de blockbusters de ese tipo hasta los años setenta, con la mucha mayor cantidad que se observa después.

Pero luego el concepto amplió su alcance. Por ejemplo, Nina Kokkinen argumentó que, además de como fenómeno histórico preciso derivado de la contracultura, se podía emplear como constructo teórico o herramienta de análisis observable también en otras épocas, un campo discursivo de buscadores de una verdad oculta; en ese proceso en ocasiones esos buscadores toman algunas obras de arte como sagradas o al menos como reveladoras de la trama secreta del mundo. ${ }^{7}$ De hecho, el amplio eco del

\footnotetext{
5 Partridge, C. The Re-Enchantment of the West. Volume 1. London / New York, T\&T Clark International, 2004, p. 43.

${ }^{6}$ Partridge, C. (2005), Op. cit., pp. 66-86.

${ }^{7}$ Kokrinen, N. «Occulture as an Analytical Tool in the Study of Art», en Aries n. ${ }^{\circ} 13$ (2013), pp. 11 y 31.
} 
que ha gozado la etiqueta en el mundo académico ha hecho que en la actualidad se entienda más en esa acepción mayor, casi como sinónimo de pensamiento mágico en lo artístico, como puede comprobarse en The Occult World, libro editado por Partridge en el 2013 y que bajo esa etiqueta engloba estudios sobre arte y esoterismo medieval y renacentista, por ejemplo.

Por ello, aunque las raíces de la occulture se hallen en la contracultura de los años cincuenta y sesenta, también se encuentra en la literatura fantástica romántica, ${ }^{8} \mathrm{o}$ heredera de este movimiento, con lo esotérico como horizonte cultural en autores como E.T.A. Hoffmann, Edward Bulwer-Lytton y Gustav Meyrink. De hecho, una parte significativa de la literatura fantástica históricamente ha tenido mucha relación con la occulture en sentido amplio, dadas sus características, de literatura en general popular, que amenaza a lo que un contexto sociocultural determinado considera real, con posible origen sobrenatural, según la definición de Roas. Suscita un efecto de incertidumbre hacia la percepción de la realidad y sobre la autoconciencia del yo. Por ello, la amenaza a lo real lleva a plantearse la impensada existencia de una realidad alternativa, imbricada en la hasta entonces tomada como pétrea, de ahí que Roas titule así su ensayo. ${ }^{9}$

Pero respecto a los autores de fantástico románticos o simbolistas, incluso los más próximos al ocultismo, existe una diferencia de grado y cuantitativa. La brujería se inscribe en la narración como algo normal, existente sin duda. Un ejemplo se encuentra en la manera de exponer la brujería, con los cambios de posición constatables en clásicos fílmicos como Häxan (La brujería a través de los tiempos, 1922) o teatrales como Las brujas de Salem (1953), en las que la hechicería se interpreta como un problema psicológico, de unas mujeres que sufren delirios a causa de la opresión social que sufren. Ahora bien, lejos de ser unas personas perturbadas sufriendo alucinaciones, en películas o series de los últimos años como American Horror Story: Coven (2013), Suspiria (1977, 2018), o La bruja (2015), lo sobrenatural resulta bien real, constituye el eje de lo que acontece en la pantalla. La posibilidad de lo mágico fundamenta el universo retratado, algo que, sociológicamente, coincide con la emergencia de nuevas corrientes religiosas como la Wicca.

Así, lejos de terminar el pensamiento mágico aplastado por lo religioso, y ambos rematados por el científico, como creía la antropología evolucionista de finales del $\mathrm{XIX}$, lo que ha pasado es que esa forma ritualística, simbólica y proclive al mito se ha adaptado a la nueva realidad económica, mediática y tecnológica del capitalismo avanzado. Con esas nuevas encarnaciones «we are witnessing a return to a form of

8 Kokkinen sitúa sus inicios a principios del siglo xix. En Kokkinen, N. Op. cit., p. 9.

9 Roas, D. «La amenaza de lo fantástico», en Roas, D. (comp). Teorías de lo fantástico. Madrid, Arco / Libros, 2001, pp. 7-46 
magical culture». ${ }^{10}$ En definitiva, la tesis de Partridge es que el encantamiento no ha desaparecido, sino que ha cambiado de formas.

\section{La occulture en el cómic. The Sandman: El precursor rey de los sueños}

La occulture y los principios fundamentales esotéricos, tal y como se exponen en algunos cómics de las últimas décadas, serán el eje de este artículo. Y es que si la occulture se circunscribe a la cultura popular, como sostienen Partridge y Kokkinen, pocas formas hay que lo sean más que el cómic. Por orden cronológico, se comentarán filtrados según este criterio: The Sandman (Neil Gaiman guionista, diversos dibujantes, 1988-1996), Los invisibles (Grant Morrison guionista, diversos dibujantes, 19942000), Promethea (Alan Moore guionista, J.H. Williams III dibujante, 1999-2005), Strangehaven (Gary Spencer Millidge guionista y dibujante, 1995-) y Saucer Country (Paul Cornell guionista, Ryan Kelly dibujante, 2012-2013).

Se analizará estas obras no por su papel dentro de la historia de los comic-books sino por su uso de referencias provenientes del horizonte cultural ocultista, como expositores de temas ocultistas que resultan sus motores narrativos. Tanto Moore como Gaiman o Morrison pertenecen a la que se ha denominado era de cobre ${ }^{11}$ (o moderna) de los cómics, en la que se produce una renovación completa. Los tres comparten características claramente posmodernas, con su uso de referencias a la cultura popular, su inventiva y originalidad estructural que juega con los tópicos de cada género, su potencia autorreflexiva respecto al medio del cómic, o su combinación de estratos culturales. Otro rasgo de unión entre ellos es que The Sandman (desde su número 47) o Los Invisibles fueron publicadas por la misma editorial, Vertigo, una línea de publicación especial de DC Comics, lanzada para diferenciarse de la matriz DC, mucho más mainstream. ${ }^{12}$

Debe recalcarse, además, que descuellan como grandes clásicos de ese medio artístico, más allá de esos aires ocultistas. M. Keith Booker subraya el valor de Gaiman y Moore como autores gracias a los cuales el género artístico ha ganado respeto crítico. ${ }^{13}$ O Shirrel Rhoades, para quien el impulso renovador que supuso Moore sirvió como punta de lanza de la renovación general del cómic. ${ }^{14}$

10 Partridge, C. (2004), Op. cit., p. 40.

${ }^{11}$ Algunos analistas también sitúan las primeras obras de Moore a la era previa, de bronce.

12 Rhoades, S. A Complete History of American Comic Books. Nueva York, Peter Lang Publishing, 2008, pp. 138-139. Naranjo, F. Alan Moore: magia y precisión. Madrid, Sins Entido, 2004, p. 22.

13 Booker, M. K. «Preface», en Booker, M. K. (ed.). Encyclopedia of Comic Books and Graphical Novels. Santa Barbara, Greenwood, 2010, pp. XXI-XXII.

${ }^{14}$ Rhoades, S. Op. cit., p. 112. 
Pero si Alan Moore fue la punta de lanza de esta renovación, entre los seleccionados para este análisis el primer título cronológicamente dentro de la occulture fue The Sandman, «an existential story of myth and horror», ${ }^{15}$ uno de los grandes hitos de las novelas gráficas en un momento, ${ }^{16}$ finales de los ochenta, de gran transformación del medio.

Resultaría un ejemplo canónico de lo que Beville llamó gótico posmodernista, una narrativa autoconsciente que entrelaza lo sobrenatural con lo metaficcional, teñido el conjunto de una atmósfera misteriosa para aprovechar los efectos de sublimidad del terror, que explora lo subterráneo dentro de lo cotidiano, desplegando una sobrerrealidad en la realidad. Además, la categoría muestra una querencia a lo sombrío y lo monstruoso. Otra característica posmodernista de The Sandman es que expone los mecanismos de la narración para ironizar sobre ellos y sobre la cultura mainstream. La obra de Gaiman sobresale en una de las principales virtudes del gótico posmodernista: el terror sublime, un horror que permite trascender los límites de la existencia humana para otear algo más allá. ${ }^{17}$

Argumenta Beville que el gótico ha experimentado diversas mutaciones, una de ellas en la cultura de la posmodernidad. Lo fantástico ha ido tendiendo hacia lo gótico, que ha influido además a la literatura posmodernista no fantástica, hasta el punto de que esta académica sostiene que el fantástico se ha reencarnado en el gótico posmodernista. ${ }^{18}$ Respecto al tema de este artículo, esta nueva mutación en la categoría de lo gótico ha mantenido la fascinación por lo oculto ya sentida por el horror gótico de finales del Xviı y sus continuadores. ${ }^{19}$

The Sandman destaca como ficción gótica posmodernista al basarse en personajes sobrenaturales como el protagonista que da título a la serie, señor del sueño. En la serie, lo cotidiano humano está atravesado por lo sobrenatural de seres feéricos, no físicos, pero que influyen en el plano de la humanidad. Y su forma de terror es claramente gótica, con una tendencia a buscar efectos de sublimidad, insuflado el conjunto de una atmósfera misteriosa.

De hecho, la occulture ya funciona como motor argumental del n. ${ }^{\circ} 1$, protagonizado por una sociedad secreta de magos, la Orden de los Antiguos Misterios, notoria refe-

15 Idem.

${ }^{16}$ Isabella escoge un número (n. ${ }^{\circ}$ 19) como de los mejores de la historia del cómic, un número que mereció el World Fantasy Award del 91: Isabella, T. 1000 Comic Books You Must Read. Iola, Krause Publications, 2009 [e-book], p. 166.

17 Beville, M. Gothic-postmodernism. Amsterdam, Rodopi, 2009, p. 15 y ss.

18 Ibid., p. 94.

${ }^{19}$ Ibid., p. 55. 
rencia a la Hermetic Order of the Golden Dawn y a Aleister Crowley. ${ }^{20}$ En el primer arco argumental, que se extiende del n. ${ }^{\circ} 1 \mathrm{al} \mathrm{n.}{ }^{\circ} 7$, titulado Preludios y nocturnos, se explica cómo es recreado el reino de los sueños, gobernado por Morfeo, una vez que este se libera de la Orden de los Antiguos Misterios, la cual, impulsada por su líder y trasunto de Crowley, lo ha encarcelado durante décadas. Este personaje había invocado a Morfeo pensando que acudiría su hermana Muerte. Pero se personó este, señor del reino de los sueños, protagonista de la colección y hombre de arena del título, una referencia proveniente de la mitología celta. El personaje de Gaiman a menudo es citado como ejemplo por antonomasia de superhéroe posmoderno, complejo, con reacciones imprevistas, de gran poder de atracción y potencia emocional. ${ }^{21}$

En los primeros capítulos aparece un personaje con uno de los nombres más relevantes en el ámbito esotérico anglosajón: John Dee, es decir, el famoso mago que trabajó a las órdenes de la reina Elizabeth de Inglaterra, en la segunda mitad del siglo xvi. ${ }^{22}$ Con todo, el John Dee sandmaniano no guarda relación con aquel: se trata de un loco, hijo de una ladrona de la Orden de los Antiguos Misterios, quien robó una joya que concentra el poder de Morfeo; con dicho dispositivo, el loco John Dee provoca veinticuatro horas de locura en las que el mundo de vigilia y el de los sueños se funden en una pesadilla. Pero el John Dee loco se presenta de una manera que suscribiría el consejero de la reina Elizabeth I, como filósofo hermético además de científico, lo que entronca directamente con aquel.

El uso de un universo ocultista cambia las reglas del mundo expuesto, haciéndolo mágico. Pero no solo modifican la ontología de ese cosmos desde su raíz, también la forma de incorporar la información a las viñetas, así como su diseño, que rompe la cuadrícula rectangular formada por series uniformes de rectángulos más pequeños o incluso en ocasiones su lectura de derecha a izquierda y de arriba abajo, incluso su disposición, de forma que obliga a girar el volumen.

Con la ruptura de la rejilla se añade capacidad expresiva, impacto visual y fuerza dramática. Esta tendencia a la disposición orgánica no constituye propiamente una novedad del título, ya que hay otros previos como La cosa del pantano (guionizada durante

20 Gilbert, R.A. «Hermetic Order of the Golden Dawn», en Hanegraaff, W.J. (ed.). Dictionary of Gnosis $\mathcal{E}$ Esotericism. Leiden - Boston, Brill, 2006, pp. 544-550. PAsı, M. «Crowley, Aleister (born Edward Alexander)», en Hanegraaff, W. J. (ed.). Op. cit., pp. 281-287.

${ }^{21}$ Rhoades, S. Op. cit., p. 131.

22 Entre otros temas esotéricos, Dee se interesó por un supuesto lenguaje de los ángeles, el enochiano (del profeta, último hombre mortal en hablarlo), fruto de sus sesiones espiritistas, cuando creía comunicarse con ángeles (en Asprem, E. Arguing with Angels. Enochian Magic E̋ Modern Occulture. Albany, Sunny Press. State University of New York, 2012), tema que volverá a aparecer más adelante en este artículo. La monografía más relevante de las últimas décadas sobre el ocultismo del diplomático isabelino es la de Szonyi: Szonyi, G. E. John Dee's Occultism. Magical Exaltation through Powerful Signs. Albany, State University of New York Press, 2004. 
una época por Alan Moore) que ya lo exploraban. Pero en The Sandman esa tendencia se agudiza. Por ejemplo, según especifica Julia Round, en el primer capítulo de The Sandman cada vez que interviene la magia el diseño de la viñeta florece, encuadrada por marcos ornamentados. ${ }^{23}$ Igualmente, se innovó en la tipografía de los diálogos, presentados de forma diferente al convencional blanco y negro dependiendo del personaje, como Morfeo o su hermana Delirio. ${ }^{24}$ De esta manera, el diseño de la página se adapta a menudo a las necesidades expresivas de la historia, ya que contienen sentido, una tendencia que, según se verá, prosiguió en Los invisibles y en Promethea.
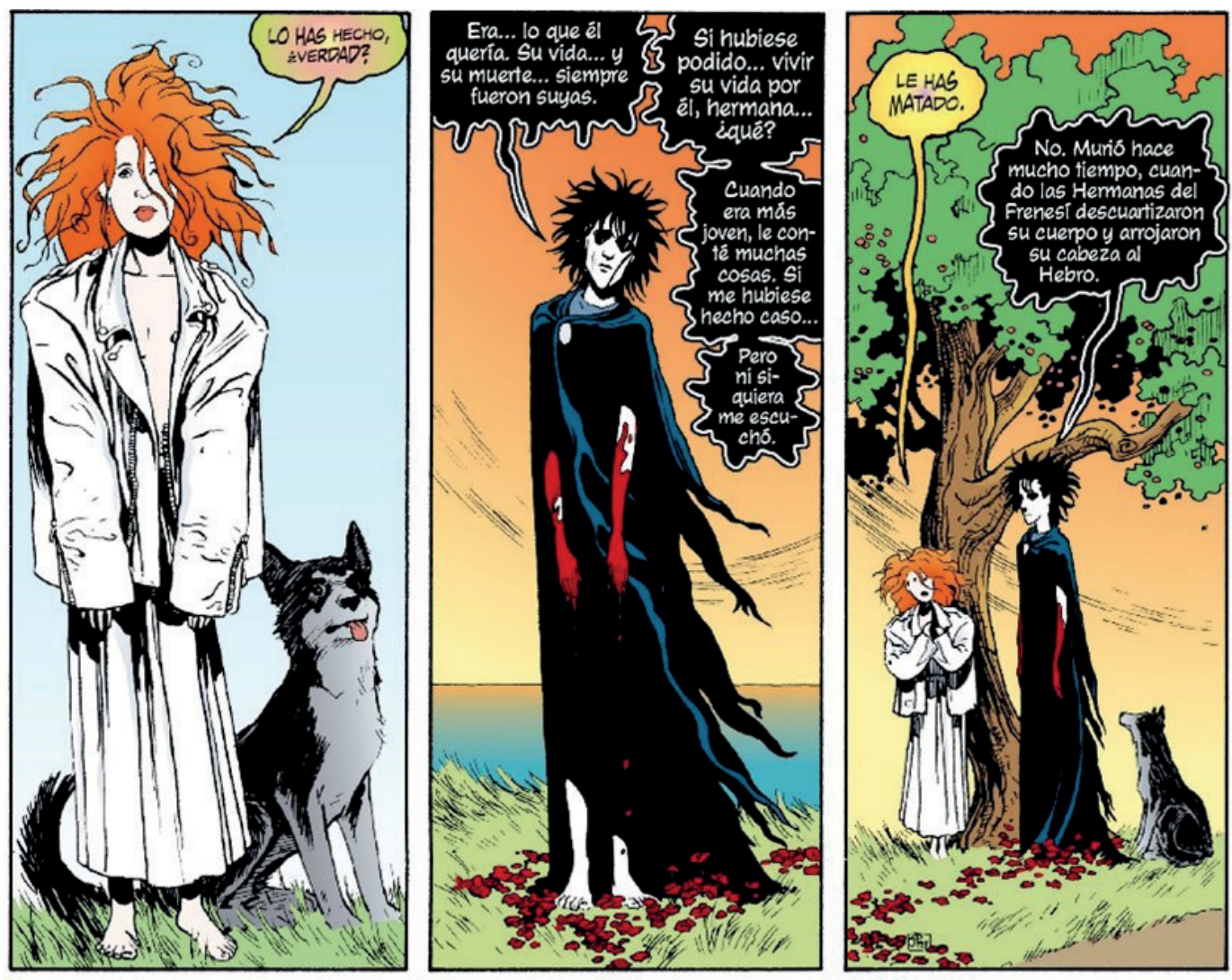

270

FIG. 1. Copyright (C) VERTIGO / DC COMICS. All rights reserved. Gaiman, G. y Thompson, J. The Sandman n. 49 (1993), p. 7. Cortesía de Vertigo / DC Comics.

${ }^{23}$ Round, J. Gothic in Comics and Graphic Novels. Jefferson, McFarland \& Company, 2014, p. 123.

${ }^{24}$ La creación de este apartado de la visualidad de la obra fue más bien una cuestión colectiva: Mc$\mathrm{CABE}$, J. Junto al rey del sueño: conversaciones con Neil Gaiman y sus colaboradores. Barcelona, Norma, 2007, p. 288. 
Pero nos ceñiremos más a la cuestión temática que a la formal. Se modifica por ejemplo el relato sobre el ciclo del mundo, concebido de manera muy diferente al relato dominante. Entre otras diferencias, se incluyen Atlántidas donde vivieron otras humanidades, en otro topos del esoterismo occidental —en especial tras el influjo de la teosofía de Blavatsky y la antroposofía de Steiner-, con personas conviviendo con grandes saurios, o incluso seres existentes antes de la condensación terráquea. El n. ${ }^{\circ}$ 43 empieza resumiéndolo un poco al comentar la existencia de los ancianos, seres humanos que compartieron espacio con los mamuts, que vivieron en la Atlántida, o incluso antes, y continúan todavía con vida. Por consiguiente, esos ancianos pueden vivir miles de años.

Sobre este tema del humano inmortal, uno de los grandes mitemas ocultistas, por así expresarlo, citado con variantes muy diversas en algunas de sus corrientes, resulta central en otro de sus números, el n. ${ }^{\circ} 13$. En este caso, y a diferencia de los ancianos recién apuntados, el superhombre logra la inmortalidad gracias a su voluntad, férreamente decidido a no fallecer.

Además de la inmortalidad, la reencarnación constituye otro tema de este horizonte cultural esotérico, por ejemplo, así concluirá el hilo narrativo de Nada (n. ${ }^{\circ} 9$, n. $^{\circ} 21$, n. $\left.{ }^{\circ} 22\right)$. Esta mujer rechazó el amor de Morfeo, obligada por las circunstancias. Por ello fue castigada a pasar miles de años en el infierno regentado por Lucifer. Finalmente, ella y Morfeo pueden llegar a un pacto: las circunstancias — su condición humana-, siguen impidiendo el amor, pero Nada puede reencarnarse y gozar de otra vida fuera del infierno.

Y todavía hay otro tipo de personaje que roza la inmortalidad: los dioses. De hecho, en el comic-book aparecen pertenecientes a un gran número de religiones, desde Odín a Anubis. Es más, en el mundo de The Sandman algunos dioses han dejado de serlo para camuflarse entre los humanos (.$^{\circ} 44$ ) y ejercer, por ejemplo, de grandes magnates de los servicios de transporte. O Ishtar, quien trabaja como showgirl.

También intervienen como personajes grandes figuras del mundo judeocristiano, como el ya mencionado Lucifer. El reino del inframundo sirve de objeto de una de las series de capítulos de The Sandman, Estación de nieblas (n. ${ }^{\circ} 21-\mathrm{n} .{ }^{\circ} 28$ ), ${ }^{25}$ cuando Lucifer decide despedirse de su papel de rey de esas tierras. Ese arco de historias trata sobre quién debe ser el nuevo dios del reino infernal, que acabará siendo gobernado por dos ángeles enviados por Dios con ese propósito, lo cual supondrá una nueva tortura, aún más sofisticada: la redención.

25 The Sandman está muy documentado respecto a las religiones, lo mítico y el esoterismo. A título probatorio, en uno de los episodios de Estación de nieblas, el n. ${ }^{\circ} 22$, mientras se prepara un descenso de Morfeo al infierno, se informa de la secta gnóstica de la Antigüedad tardía de los cainitas; se domina ese horizonte cultural con referencias que van más allá de las mejor conocidas. 
Finalmente, un rasgo fundamental de The Sandman, no exclusivamente ocultista pero sí vinculado, es el del placer por lo narrativo, ${ }^{26}$ con cada relato equiparado a un sueño, en el que Morfeo actúa de dios regente.

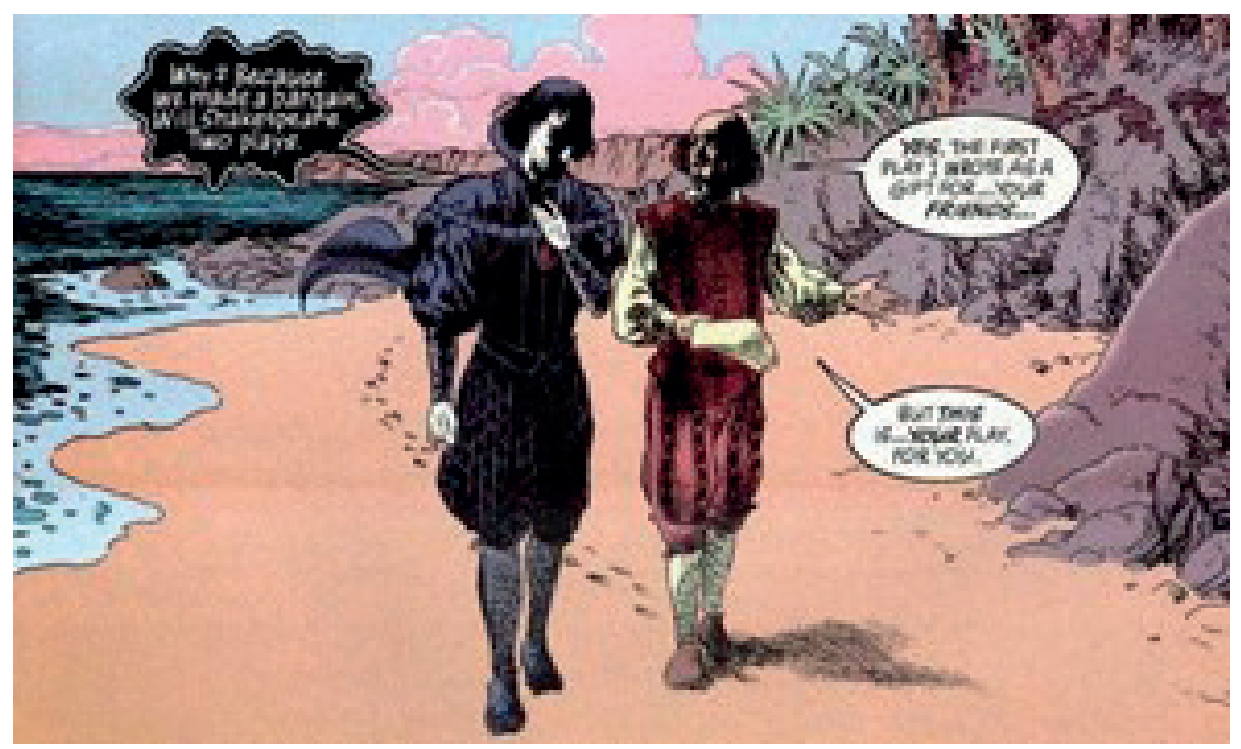

FIG. 2. Copyright (C) VERTIGO / DC

COMICS. All rights reserved. GaIman,

N. y Vess, M. The Sandman n. ${ }^{\circ} 75$ (1995),

p. 22. Cortesía de Vertigo / DC Comics.

\section{La occulture más conspiranoica: Los invisibles}

Ese mismo goce por la narración se repite en Los invisibles, serie guionizada enteramente por Grant Morrison, pero en la que participaron diversos dibujantes. ${ }^{27}$ Respecto al tema de este artículo, Los invisibles se postula como un gran expositor de temas y citas ocultistas, incluso con un acopio de citas mayor que en la serie anterior.

Con todo, si la piedra axial que sostiene The Sandman radica en la quintaesencia de lo onírico y la narración, la de Los invisibles, pasa a basarse en el recelo conspiranoi-

${ }^{26}$ Entre las muchas destrezas narrativas y textuales de la serie, William Grady apunta que Gaiman fue de los primeros en utilizar una voz narrativa heterodiegética en tercera persona. En Grady, W. «Transcending the Frontier Myth: Dime Novel Narration and (Jesse) Custer's Last Stand in Preacher», en Pustz, M. (ed.). Comic Books and American Cultural History. New York, Continuum, 2012, p. 56, n. 34.

27 Este título y The Sandman contradicen a Antonio Altarriba cuando afirmaba que en los cómics se identifica al autor con los dibujantes. Claro que Altarriba se refiere a un periodo de la historia del medio previo al de los autores comentados aquí, y que en el mundo anglosajón está tendencia de identificación nunca fue tan intensa como en la Europa continental: Altarriba, A. «Características del relato en el cómic», en Neuróptica, n.o 1 (1983), p. 16. 
co. ${ }^{28} \mathrm{El}$ cómic presenta una tendencia ideológica antisistema. Entre los ejemplos de este artículo probablemente este título resulte aquel más situado en el radicalismo político de raíz anarquista. Aunque también Alan Moore presenta una clara querencia por ello, es en Los invisibles donde más se enfatiza la desconfianza hacia las élites o los diversos poderes, hasta devenir en buena medida el motor narrativo principal, siempre desde una perspectiva que hermana ese marco mental con el esoterismo.

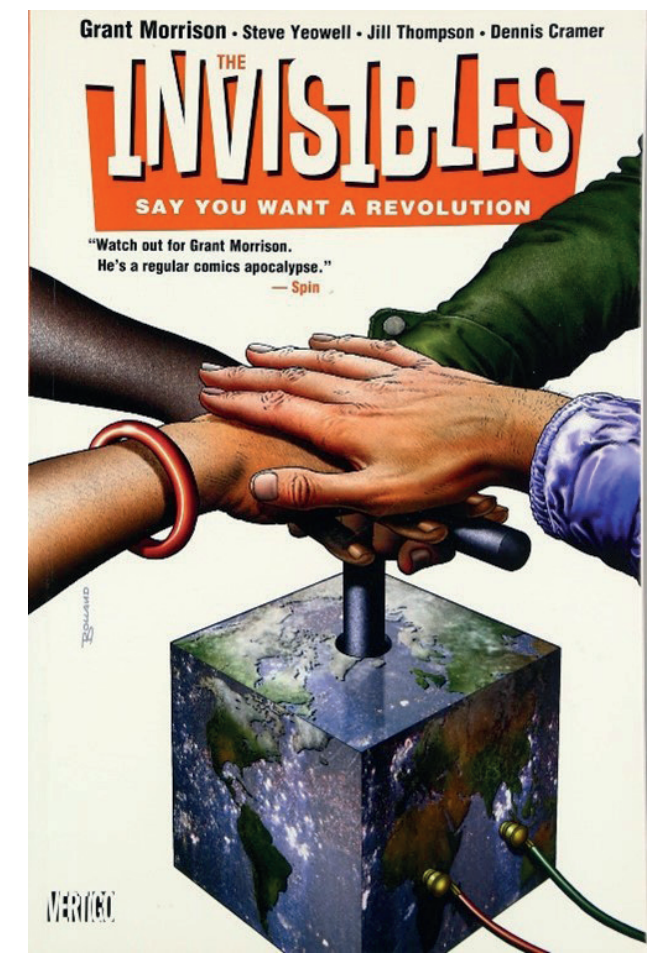

FIG. 3. Copyright (C) VERTIGO / DC COMICS. All rights reserved. Morrison, G. Weston, C. y Stokes, J. Los invisibles, volumen 2, n. ${ }^{\circ} 22$ (1999), portada. Cortesía de Vertigo / DC Comics.

Como toda obra contracultural «antisistema», utiliza los temas favoritos de la sospecha. Como mitema inicial de la conspiranoia, el control mental impuesto por los

${ }^{28}$ Las teorías conspirativas constituyen uno de los lineamientos del esoterismo, mezclado con el milenarismo a partir de la emergencia del fenómeno New Age, uno de cuyos textos canónicos se titulaba precisamente La conspiración de Acuario, aunque sin el sentido peyorativo que irá adquiriendo el término "conspiración". Sobre el milenarismo de la corriente: HanegraAfF, W. J. New Age Religion and Western Culture. Leiden-New York-Koln, Brill, 1996, p. 98 y ss. Probablemente la forma fantasiosa de entender la francmasonería, junto al antisemitismo, haya multiplicado ese tipo de pensamiento. Sobre masonería y teorías de la conspiración: LiAgre, G. «Freemasonry and Protestantism», en BogDAN, H. y Snoek, J. A. M. (eds.). Handbook of Freemasonry. Leiden / Boston, Brill, 2014, p. 176 y ss. 
gobernantes - básicamente el Reino Unido y los USA, aunque se colige que también el resto de «élites»— para dominar a la población mundial. Los malvados señores que controlan el mundo se llaman archones, cita directa a los arcontes gnósticos. ${ }^{29}$ Ellos intervienen como aquellos que dominan el universo físico y esclavizan a los humanos. El sentido de los archones en el cómic resulta, pues, muy cercano al de los arcontes gnósticos, juzgados de manera muy negativa.

Pero frente a ellos se alza otra élite rival, la de los invisibles, una sociedad secreta de iniciados en los misterios, la cual lucharía a favor de la libertad humana, instigadora de las revoluciones francesa y estadounidense, con los illuminati como fraternidad arquetípica. De hecho, esa cuestión se sugiere ya desde su mismo título. Los mismos rosacruces fueron conocidos como los Invisibles, como se autodefinían. ${ }^{30} \mathrm{O}$ también cabe recordar al colegio invisible de filósofos naturales precursores de la mentalidad científica, que pusieron las bases del método mientras investigaban en la alquimia, caso de Robert Boyle. ${ }^{31}$

Junto al gobierno mundial manejado por una élite infame, aparecen muchos otros de los argumentos favoritos dentro del imaginario ocultista conspiranoico. Por ejemplo, el virus del SIDA habría sido probado primero y difundido después desde una base militar en el que trabajarían aliados los estadounidenses y extraterrestres. Si se estira este hilo argumental, en el n. 5 del vol. 2 se dialoga sobre otro de los grandes temas del recelo contemporáneo: las grandes farmacéuticas disponen de curas para todo, pero no las ofrecen al público, ya que los enormes beneficios económicos que reciben se basan en la enfermedad, de manera que los medicamentos la prolongarían en vez de curarla o cuando menos paliarla.

O el aprovechamiento de sistemas de dominio psíquico aprendidos gracias al OVNI que supuestamente se estrellara en Roswell. Y es que el papel del lenguaje y el del dominio o esclavitud psicológica que puede acarrear aparece de continuo y con variantes tan diversas como el de una supuesta lengua primordial, que ha tomado nombres diversos, como angélica o prebabélica, simplemente lengua secreta en Los invisibles. ${ }^{32}$

29 Arconte en inglés es archon, pero probablemente el traductor de la obra no conocía el gnosticismo. En varios autores de la corriente religiosa gnóstica los arcontes se correspondían con los planetas, los siete dioses planetarios, señores de los vicios, que intervenían para producir el cuerpo psíquico de cada ser en el que, por tanto, imprimían dichos vicios: Couliano, I. P. Experiencias del éxtasis. Barcelona, Paidós, 1994, pp. 122-128; Luttikhuizen, G. P. «The Demonic Demiurge in Gnostic Mythology», en Auffarth, C. y Stuckenbruck, L. T. (eds.). The Fall of the Angels. Leiden-Boston, Brill, 2004, pp. 148-160.

${ }^{30}$ Yates, F. A. Giordano Bruno y la tradición hermética. Barcelona, Ariel, 1983, p. 504.

31 Newman, W. \& Principe, L. Alchemy Tried in the Fire: Starkey, Boyle, and the Fate of Helmontian Chymistry. Chicago, University of Chicago Press, 2005

32 Ursini, F., Mahmutovic, A. y Bramlett, F. «Which Side Are You On? The Worlds of Grant Morrison». Conference Paper, [sin más datos], 2014. Disponible en https://www.researchgate.net/ publication/314875769 Which side are you on The worlds of Grant Morrison [último acceso $11 / 12 / 2020]$, pp. 21-22. 
Una tesis del lenguaje como constructor de percepción y, así, de realidad, que une el posestructuralismo (como bien indica Ramos) ${ }^{33}$ con la cábala, de manera que quien domina ese lenguaje primordial ha entrado en la esencia de la vida, su nivel ontológico fundamental, que restaura la escisión lenguaje-realidad y materia-espíritu.

Entre las diversas formas de concebir la magia y lo esotérico se privilegian aquellas variantes con un fuerte componente espectacular, las que pueden suscitar más impacto. Por ejemplo, citas al neochamanismo de Castaneda (vol. 2, n. ${ }^{\circ}$ 2), las vinculadas con enteógenos o drogas alucinógenas, con comentarios sobre Terence McKenna o William S. Burroughs, ${ }^{34}$ la psicología transpersonal de Stanislav Grof, o también la magia ceremonial tipo Aleister Crowley. Estos tipos de temas, estrellas o corrientes ocultistas resultan privilegiados por encima de aquellos otros más austeros o más interesados en lo metafísico en sí.

De hecho, la serie descuella como compendio de referencias a los autores más destacados del ocultismo, New Age y áreas afines. ${ }^{35}$ La mezcolanza de referencias justifica el que Morrison llame a su teoría de la magia como magia pop, sin olvidar el fuerte componente sexual de la propuesta.

\section{Una diosa para lo imaginario: Promethea}

La magia tal y como yo la veo; como algo bello. ${ }^{36}$

Las dos series analizadas anticipan la occulture en el ámbito de la viñeta, pero el cetro de gran enunciador de esta sensibilidad y temática en el mundo del comic-book pertenece a Alan Moore, hasta el punto de que John Higgs se permite sostener, un tanto

${ }^{33}$ Ramos Vera, M. «Más que superhéroes: filosofía del lenguaje, perennialismo y los cimientos de la realidad en Grant Morrison», en CuCo, Cuadernos de cómic n.o 15 (2020), p. 59. Disponible en http://cuadernosdecomic.com/docs/revista15/3\%20M\%C3\%A1s\%20que\%20superh\%C3\%A9roes\%20-\%20Mario\%20Ramos.pdf

${ }^{34}$ El uso de enteógenos destaca como otro punto axial de Los invisibles. Morrison dio con el esbozo de la serie durante una visión que tuvo en un hotel de Katmandú, en lo que las drogas también tuvieron su papel: Kripal, J. Mutants and Mystics: Science Fiction, Superhero Comics, and the Paranormal. Chicago, University of Chicago Press, 2015 [e-book], pos. 488.

35 Por citar a algunos, se mencionan a Robert Turner —investigador en textos clásicos de la magia-, Von Daniken, Eliphas Lévi — de quien se cita sutilmente a su mano de sombra (n.o 5), ilustración presente en Dogma y alto ritual de la magia - el teórico de la magia del caos Phil Hine y su Pseudonomicon, Ken Wilber, Whitley Streiber (extraterrestres y abducciones). Sobre el paso de Strieber de la novela de terror a la autobiografía en la que relata como él mismo fue abducido, véase PALAcios, J. Satán en Hollywood: una historia mágica del cine. Madrid, Valdemar, 1997, pp. 223-224. O el uso del imaginario de El hombre de mimbre, filme de imaginario neopagano que, por esa razón, constituye una referencia continua en todo el tercer volumen de la serie.

${ }^{36}$ Millidge, G. S. Alan Moore: storyteller. Barcelona, Planeta de Agostini, 2012, p. 236. 
enfáticamente, que: «If you want to know about magic in the modern era, Moore is the man to ask». ${ }^{37} \mathrm{El}$ académico especializado en la historia del esoterismo Jeffrey Kripal, por su parte, señala que la manera de entender el arte del escritor bebe directamente del ocultismo, ${ }^{38}$ algo que puede atestiguar tanto su trabajo teórico Ángeles fósiles como alguno de sus cómics, especialmente el protagonizado por la heroína imaginal.

Porque si hay un título de Moore en el que esta faceta se muestra plenamente, ese es Promethea, publicado en America's Best Comics, con los dibujos de J. H. Williams III y la participación asimismo de artistas como Mick Gray y José Villarrubia. El cómic resulta un compendio de temas esotéricos. ${ }^{39} \mathrm{El}$ propio Moore comentó: «Utilizing my occult experiences, I could see a way that it would be possible to do a new kind of occult comic, that was more psychedelic, that was more sophisticated, more experimental, more ecstatic and exuberant». ${ }^{40}$ Es más, en algunos grupos esotéricos actuales el cómic ha servido como introducción a esa cosmovisión. ${ }^{41}$

Con ello, Promethea constituiría un ejemplo de lo que Kokkinen llama religioning, en su sentido de volver la cultura popular como algo sagrado, difuminando los márgenes entre literatura religiosa y otra aparentemente secular. ${ }^{42}$ De hecho, esta serie pone en duda las fronteras entre arte elevado y popular, entre espiritualidad y religión, así como entre arte y religión, siguiendo los argumentos de Kokkinen para su matización a la occulture de Partridge.

La gran cantidad de información ocultista en el cómic excedería los límites de este panorama general. ${ }^{43}$ Por ello, las siguientes páginas pivotarán sobre dos conceptos: su idea de un mundo de imaginación, en la que radica uno de los puntos esenciales del esoterismo, así como la gran destreza e inventiva formal, plenamente entrelazada con las ideas esotéricas, con la que plasma todo ello en las viñetas, dado que este artículo constituye un estudio visual sobre los cómics.

37 Higgs, J. The K.L.F.: Chaos, Magic and the Band Who Burned a Million Pounds. London, Weidenfeld \& Nicolson, 2012, p. 79.

38 Kripal, J. Op. cit., pos. 354.

39 Promethea obra de tesis (ocultista): Naranjo, F. Op. cit., p. 42. Promethea suma esotérica: Kripal, J. Op. cit., pos. 358. Promethea cómic hermético: Ferrer Ventosa, R. «Pensando en imágenes jeroglíficas», en Arte, individuo y Sociedad, 30, n. ${ }^{\circ} 2$ (2018), pp. 311-328, p. 323.

40 Kripal, J. Op. cit., pos. 378.

${ }^{41}$ Kraemer, C. H.y Winslade, J. L. "TThe Magic Circus of the Mind”: Alan Moore's Promethea and the Transformation of Consciousness through Comics», en Lewis, A. D. y Kraemer, C. H. (eds.). Graven Images: Religion in Comics and Graphic Novels. New York, Continuum, 2010, pp. 274-291, pp. 287-288.

42 Kokminen, N. Op. cit., pp. 25-26.

${ }^{43}$ Un marco esotérico que, precisamente, hizo que sus ventas cayeran, una vez se introdujo con decidida fuerza, en el número 12. Kraemer, C. H. y Winslade, J. L. Op. cit., pp. 274-275. 
Y es que la protagonista de la obra, Promethea, es un ser hecho de imaginación. Esta facultad constituye, según se acaba de anticipar, uno de los ejes teóricos del ocultismo. Así lo enunció uno de sus grandes teóricos en la academia, Antoine Faivre, con su famosa sistematización sobre qué es lo esotérico, formada por cuatro leyes fijas: un sistema de correspondencias; la noción de naturaleza viva; la experiencia de transmutación; y la susodicha imaginación, utilizada junto al uso de mediadores como objetos o imágenes. ${ }^{44}$

Ya el maestro de Antoine Faivre, Henry Corbin, había hecho de la imaginación trascendental una de sus áreas de especialización, acuñando un término para referirse a ese mundo autónomo e infinito de la imaginación que ha gozado de gran predicamento académico: lo imaginal. ${ }^{45}$ Constituye una dimensión ontológica denominada de muy diversa manera a lo largo de la historia: desde Malakût ${ }^{46}$ o ciudad esmeralda en la gnosis sufí, al reino de las hadas, o el anima mundi del platonismo y sobre todo del neoplatonismo, situada entre lo sensible y lo inteligible. Infinidad de posibilidades referidas a la esfera de lo psíquico. En este título Alan Moore lo llamó Inmateria.

Moore inventó al ser feérico Promethea, ser imaginal quien, unido a una persona, ${ }^{47}$ serviría de guía para acceder y explorar ese universo de la imaginación, inmaterial pero objetivo, al tiempo tan personal como impersonal. La heroína personifica dicho mundo. La Inmateria es el reino de la imaginación y de la magia, un lugar en el que los símbolos resultan lo único real y existen en toda su integridad (n. $\left.{ }^{\circ} 3\right)$, un mundo unitario, como el físico, por tanto, compartido por todos los seres (n. ${ }^{\circ}$ ). Las obras de arte pueden devenir petrificaciones de ese nivel de realidad, fósiles en feliz metáfora de Alan Moore, que nos capacitan para hacernos una idea de la dimensión mágica que, sin esas obras, quedaría sin manifestar. Alan Moore las estima como las «pruebas» más convincentes. ${ }^{48}$

La serie se construye a partir del horizonte cultural hermético. De hecho, ¿cómo y cuándo nació Promethea? Al final del paganismo un sacerdote hermético envía a su hija al desierto, antes de que las hordas cristianas den con ella y sufra el mismo destino fatal que el padre. Las especiales condiciones del desierto provocarán que la

${ }^{44}$ Faivre, A. «Introducción I», en Faivre, A. y Needleman, J. (eds.). Espiritualidad de los movimientos esotéricos modernos. Barcelona, Paidós, 2000, pp. 9-22 y 14-18. Fuente secundaria: Oviedo SalaZAR, M. «Reseña de Estudios sobre la historia del esoterismo occidental en América Latina», en Rehmlact, vol. 9, n. 2 (2018), pp. 288-295.

45 Corbin describe los mundus imaginalis como «el mundo autónomo de las figuras-arquetipos»: CorBIN, H. El hombre de luz en el sufismo iranio. Madrid, Siruela, 2000, p. 61.

${ }^{46}$ Conbin, H. Cuerpo espiritual y Tierra celeste. Madrid, Siruela, 1996, p. 22, 26.

47 Con ese ser dual Promethea sigue la tendencia posmodernista, apuntada por Beville, a explorar nuevas formas de pensar en el ser, que lo pluraliza, acentuando una característica que ya se encontraba en el modernismo: Beville, M. Op. cit., p. 46.

${ }^{48}$ Moore, A. Ángeles fósiles. Madrid, La Felguera, 2014, p. 136. 
niña tenga una visión, y se le aparezca el dios Hermes. Él le propondrá que viaje a Inmateria, reino en el que cambiará de estado, de lo físico a la naturaleza del cuento; se convertirá en un ser narrativo. Así que ella nace, como el hermetismo del que es deudora, en la cultura alejandrina de la Antigüedad tardía.

El cómic traza continuos paralelismos entre las peripecias que narra y los puntos esenciales del ocultismo entendido a la manera contemporánea, es decir, heterogénea y sincrética. Se trata de un ocultismo que une el hermetismo de la Antigüedad tardía o del Renacimiento, con el tantrismo, la New Age, cierta filosofía continental, la psicología transpersonal, el pensamiento simbólico masón, la magia ritual a lo Crowley, junto a muchas otras influencias próximas de una manera esencial o simplemente contingente con el esoterismo.

Por lo que se refiere a la gran inventiva formal, la serie de 32 números resulta asombrosa. En casi cada página y viñeta se desarrollan soluciones originales. La narrativa de Promethea ofrece un despliegue complejo, en ocasiones lineal, pero también juega con las simetrías, los saltos temporales, la disposición de secuencias en paralelo... acompañado por soluciones visuales muy variadas adaptadas a dicha complejidad.

Apunta con razón Thierry Groensteen una característica que se adapta también a Promethea: la variedad de estilos rompe con la búsqueda de armonía del clasicismo, con su mantenimiento de la unidad. ${ }^{49}$ Rasgo posmoderno que viene del modernismo de un Joyce, en el cómic del tándem Moore / Williams III la variedad estilística utilizada en cada caso se adapta a la que resulta más adecuada para las intenciones expresivas de los creadores. Se trata de un rasgo posmoderno, equivalente por ejemplo al de Pynchon en El arco iris de la gravedad..$^{50}$

El ingenio narrativo-formal lleva a que una escena de sexo (n. $\left.{ }^{\circ} 10\right)$ entre la protagonista y un viejo mago se convierta en sexo tántrico metafísico, que va de la sordidez de su presente en un cuchitril a la experiencia última de amor cósmico en términos neoplatónico-tántricos, por inventar un neologismo de una escuela que no existe, y que uniría a Ficino con el budismo tántrico tibetano. Siguiendo la clasificación propuesta por Antonio Altarriba, ${ }^{51}$ la escena utiliza una composición simbólica, en la que juega a asociarse con la forma del caduceo hermético, que plasma la teoría del amor no-dual tántrica, en la que se combina lo masculino con lo femenino.

${ }^{49}$ Groensteen, T. Bande dessinée et narration. Paris, Presses Universitaires de France, 2011, p. 125.

${ }^{50}$ Sobre el posmodernismo de Moore, Millidge califica específicamente como tal algunas series de Moore, como From Hell o el Black Dossier para la League of Extraordinary Gentlemen. En Millidge, G. S. Op. cit., p. 174 y 216.

51 Altarriba, A. Op. cit., pp. 31-36. 
En esa escena de amor se explica la historia del mundo, desde una cosmogonía al presente, narrada por las dos serpientes del caduceo hermético, aquí Mike y Mack, por micro y macrocosmos, otra de las ideas nucleares del pensamiento esotérico. La historia se explica según cierto evolucionismo espiritualista, como en diversos autores New Age y transpersonales. ${ }^{52} \mathrm{O}$ la manera de dibujar, partiendo de fotografías, los últimos números, dedicados a un apocalíptico final del mundo que lo metamorfosea, siendo lo apocalíptico otra de las ideas más repetidas en tantas corrientes espirituales y un mitema dentro del esoterismo occidental..$^{53}$

En medio de esa exuberancia formal destaca especialmente el n. ${ }^{\circ} 12$, un cómic de gran brillantez. Cada página contiene tres registros de información, pero sin dividirlas por ello en viñetas, ya que cada hoja (de hecho, cada doble hoja) constituye una unidad: uno de los registros está formado por una anécdota protagonizada por Aleister Crowley, otro de los niveles expone una teoría de la magia explicada a partir de los veintidós arcanos mayores del tarot del mismo Crowley, uno por página; finalmente, en cada una de ellas se combinan las letras de Promethea, que son las mismas que metaphore, para dar nuevos juegos de palabras. ${ }^{54}$

Con ello, los arcanos mayores de la baraja se convierten en percutores de una teoría sobre la magia que tiene consecuencias en una cosmología y una ontología del ser. Como Crowley está tan presente, las cartas que se exponen siguen su tarot, cambiando algunas respecto a la baraja de Marsella, como la Lujuria en lugar de la Fuerza, el Arte por la Templanza, el Eón por el Juicio y el Universo por el Mundo. Las veintidós cartas pasan a ser caminos a la comprensión de los misterios últimos del mundo y del ser humano. También se explican desde esos códigos simbólicos las edades del ser

${ }^{52}$ Esa lectura evolucionista lleva a situar a Moore, dentro de los nuevos movimientos espirituales, en una posición compleja, que combina una sensibilidad tanto posmoderna como moderna, dentro de la tipología establecida por Dawson. Este sociólogo de la religión señaló diferencias entre corrientes más modernas, antimodernas y posmodernas. DAwson, L. L. «Anti-Modernism, Modernism, and Postmodernism: Struggling with the Cultural Significance of New Religious Movements», en Sociology of Religion, 59, n. 2 (1999), pp. 131-156. Se podria definir a Moore como un posmoderno que integra características modernas: como estos últimos, Moore es holístico, evolucionista y defensor de una «verdad», aunque al tiempo esta sea proteica, su teología sea sincrética, demuestre un espíritu lúdico notorio y siempre recubra sus creaciones de ironía, es decir, con rasgos claramente posmodernos. En cambio, Morrison se muestra mucho más antimoderno.

53 Según reflexionó uno de los especialistas en esta mentalidad, Barkun: «Earth changes refers to imminent cataclysmic events affecting all or most of the planet, involving dramatic alterations such as massive earthquakes, the meeting of the polar ice cap, and the shifting of the planet's axis. These predictions occur frequently in New Age literature». En Barkun, M. A Culture of Conspiracy. Apocalyptic Visions in Contemporary America. Berkeley, University of California Press., 2003, p. 172. Este factor también se analiza por el investigador académico en la historia del esoterismo Wouter Hanegraaff, en Hanegraaff, W. J. «Alan Moore's Promethea: Countercultural Gnosis and the End of the World», en Gnosis. Journal of Gnostic Studies n. ${ }^{\circ} 1$ (2016), pp. 234-258.

${ }^{54} \mathrm{E}$ l ocultismo ha tenido una fructífera relación con las permutaciones de letras, desde la esteganografía de Tritemio y otros códigos cifrados al uso de palíndromos (el más famoso es el presudopalíndromo abracadabra), los cuadrados mágicos de letras, como sator-rotas o los anagramas. 
humano. Sobre ese número de Promethea declaró Moore: «probably the most experimental story I have ever done». ${ }^{55}$

Juegos similares de composición simbólica se desarrollan en otro de los arcos argumentales, dedicado a un viaje a Inmateria. En ese viaje más allá de lo físico se ordena según el árbol de la vida de las sefirots, que sirve para explicarse el tránsito de la vida y de la muerte. Además, el orden de exposición se basa en la estructura de la cosmología clásica en siete planetas y las correspondencias, que como ya se indicó, era para Antoine Faivre un punto clave en el esoterismo occidental.

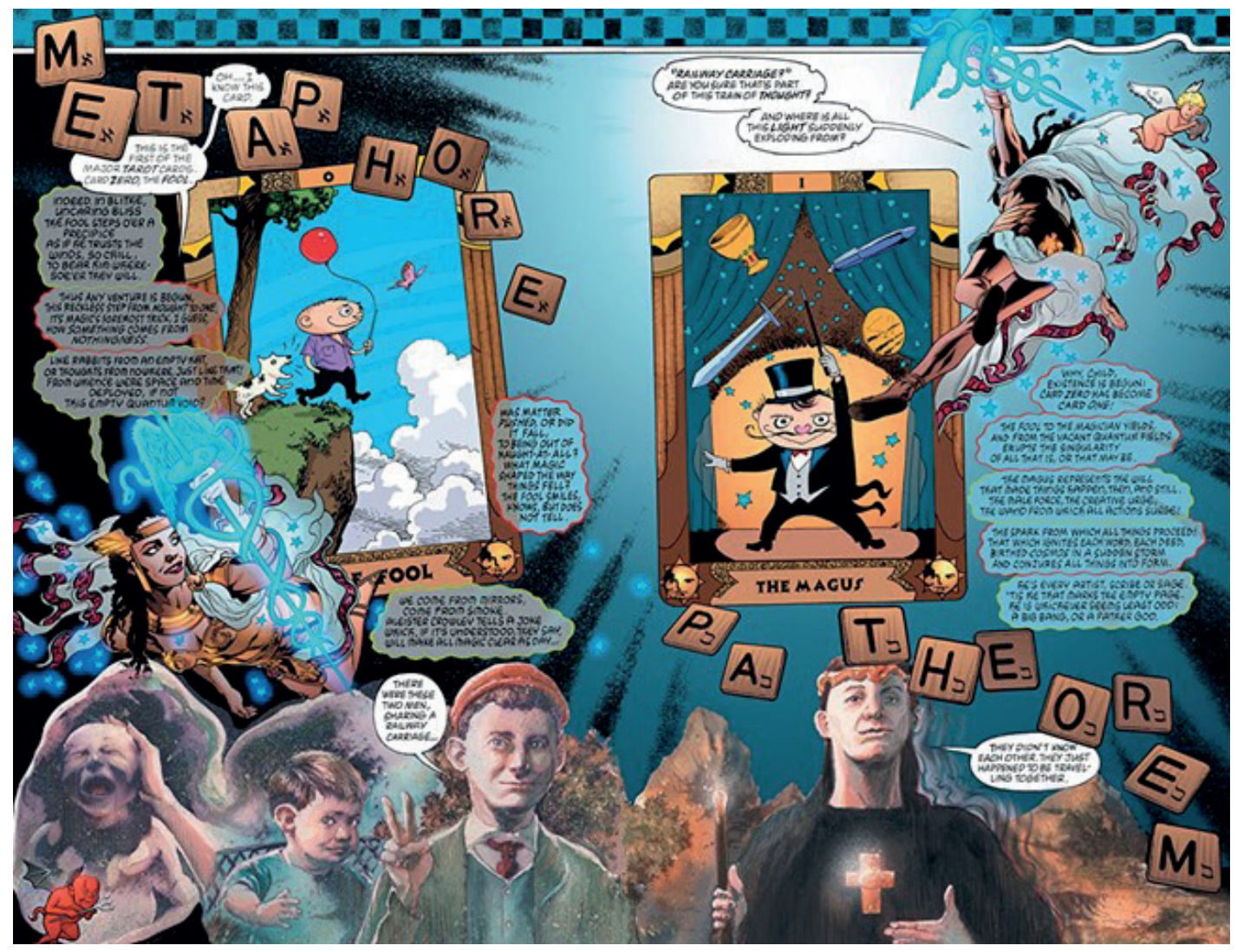

FIG. 4. Copyright (C) VERTIGO / DC COMICS. All rights reserved. Moore, A., Williams III, J.H. y Gray, M. Promethea, n. 12 (2001), pp. 3-4. Cortesía de Vertigo / DC Comics.

En esa larga serie, en el ecuador del cómic, la Promethea naciente, encarnada en Sophie, va al Otro Mundo para ayudar y para despedirse de su predecesora, que acaba de morir. El viaje permite revisar muchos de los temas cosmológicos y ontológicos

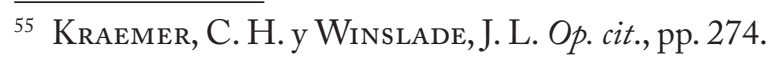


del esoterismo, entendido en la tradición europea que va del hermetismo hasta el presente, pasando por el ocultismo del xix o la magick crowleyiana del siglo xx. Ello lleva a que J. H. Williams adapte el color del dibujo al color dominante en cada planeta según la teoría de las correspondencias. Se sirve de ellos con fines expresivos, en composiciones simbólicas, en una plasmación de lo afirmado por McCloud de protagonizar escenas desde la faceta de la coloración del cómic. ${ }^{56}$ Según el marco conceptual del hermetismo neoplatónico, existen correspondencias entre planetas, estado de ánimo, metales, materiales y colores, entre otros. En el número de Promethea en que pasan por Venus, el tono se vuelve verde, mientras que en Marte predomina el rojo o en Júpiter el azul. Lo mismo sucede con los elementos: agua en Venus, fuego en Marte. Sin olvidar las correspondencias con las sefirot y los veintidós senderos de la cábala.
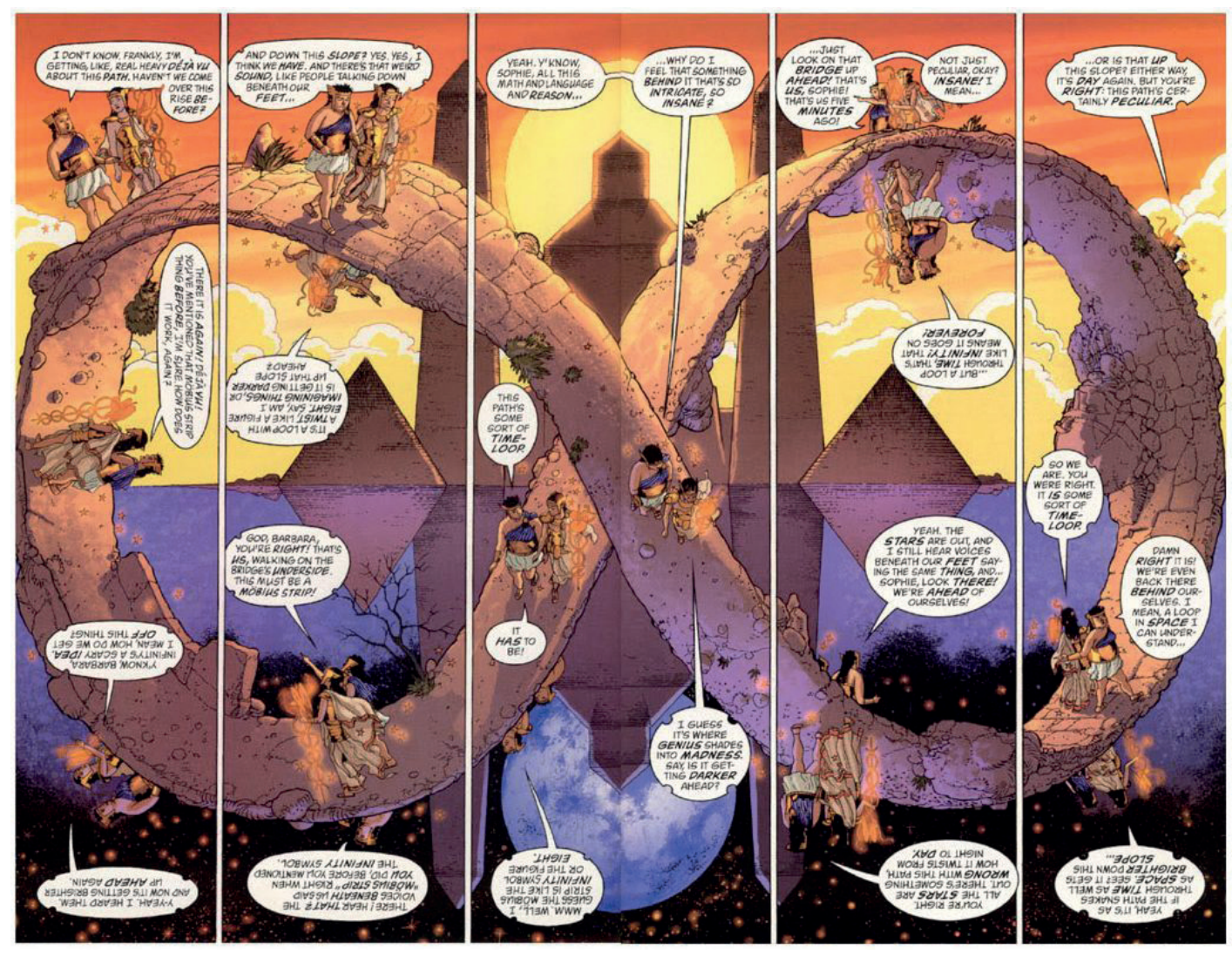

FIG. 5. Copyright (C) VERTIGO / DC COMICS. All rights reserved. Moore, A., Williams III, J.H. y Gray, M. Promethea, n. 15 (2001), pp. 8-9. Cortesía de Vertigo / DC Comics.

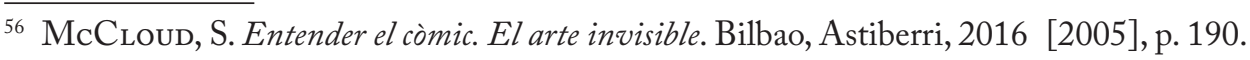


Otros juegos formales propuestos por el tándem Moore / Williams III incluyen que el volumen deba ser girado noventa grados para leerlo, ya que el número está compuesto para leerse como un papiro, con la doble hoja unida para ser leída así entera, verticalmente, como sucede en el n. ${ }^{\circ} 11$.

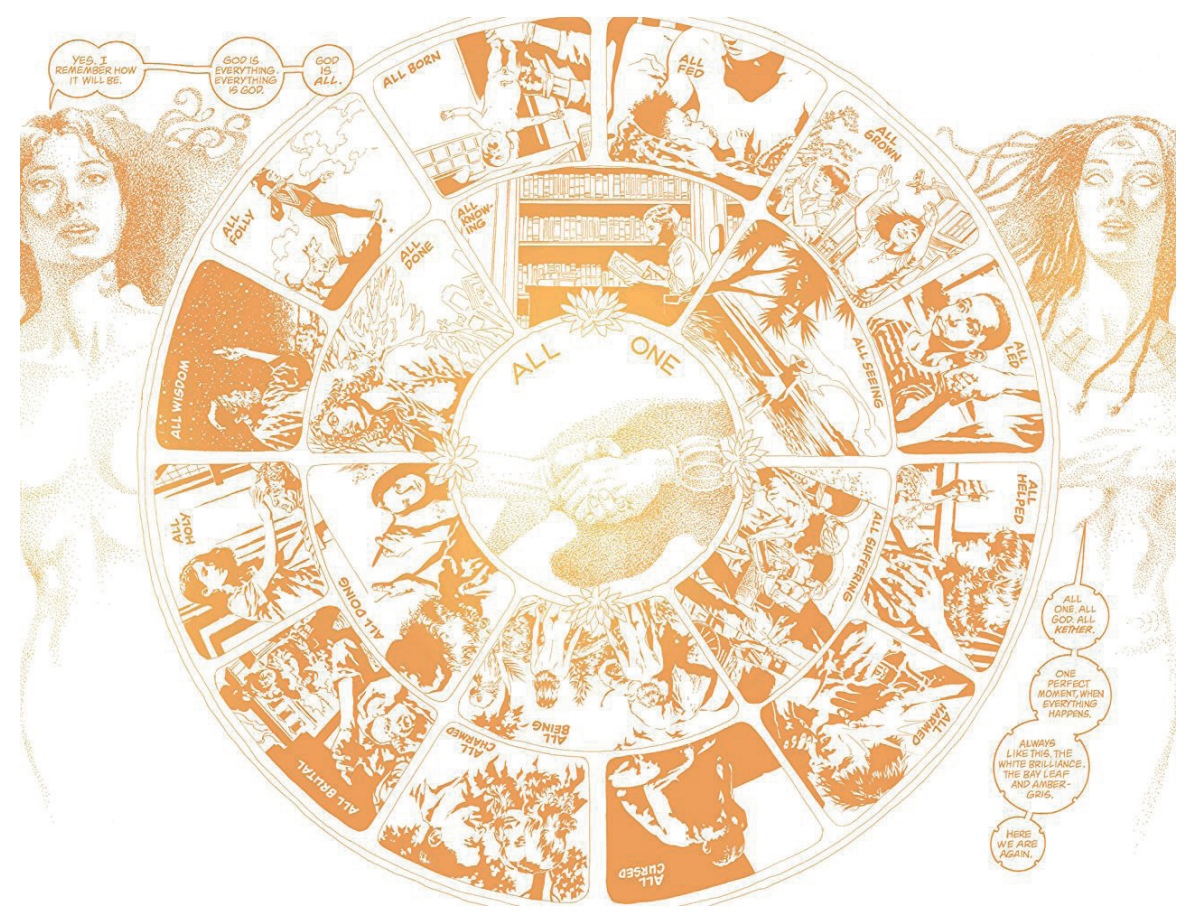

FIG. 6. Copyright (C) VERTIGO / DC COMICS. All rights reserved. Moore, A., Williams III, J.H. y Gray, M. Promethea, n.o 23 (2002), pp. 6-7. Cortesía de Vertigo / DC Comics.

O una página doble en el n. ${ }^{\circ}$ 15, unificada por una banda de Möbius, que es a la vez el signo de infinito y el ocho girado. ¿La razón de ello? Dentro del arco argumental ya comentado, que pasa por los siete planetas de la cosmología clásica y la energía simbólica que canalizan (por expresarlo en terminología ocultista), se hallan en la octava sefirot, la que se corresponde con Hermes y el planeta Mercurio. La banda representa a ese planeta, así que la composición simbólica busca soluciones ingeniosas para mostrarlo visualmente. Además de la razón formal, existe otra de índole técnica: Moore compuso tantas escenas a doble página o página extendida porque esta constituía la estructura predilecta de J. H. Williams III, según este le había confesado. ${ }^{57}$

El arco concluye con una estancia en Kéter, la Corona esplendorosa, la sefirot cabalística más elevada, con lo que supone de sumergirse en una experiencia divina,

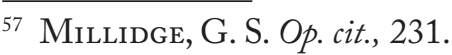


explicada en el n. ${ }^{\circ} 23$ de una manera muy original, con una explosión de luz pura, de nuevo jugando con los colores, las formas y el formato. Otra vez encontramos páginas extendidas, con una única imagen ocupando la doble página, que detienen el ritmo de la narración para obtener un fuerte impacto visual. ${ }^{58}$ De entre los diez números en los que se pretendía establecer una simbología del color, dentro de este arco argumental, este número fue el más complicado de colorear, ya que debía mostrar diversos matices y gradaciones del blanco, con la dificultad consiguiente,,$^{59}$ en un cómic que se aproxima a la visión mística, con el esfuerzo de ingenio visual y expresivo que ello comporta.

Referente a ello, el propio Alan Moore afirmó que con Promethea había llevado los recursos y posibilidades del medio tan lejos como él había sido capaz de llegar. ${ }^{60}$ Una virtud del cómic también elogiada por los analistas. Por ejemplo, en su estudio sobre Alan Moore, Gary Spencer Millidge afirma con rotundidad que la serie «contiene algunas de las experimentaciones formales más radicales de la historia del cómic». ${ }^{61}$ Esta valoración de este investigador resulta particularmente interesante, ya que se trata del creador del siguiente título que se comentará en este artículo, Strangehaven.

Pero antes de pasar a dicha serie, conviene apuntar un factor que hace este cómic aún más singular. Los personajes de Moore resultan complejos, por superhéroes que sean, uno de los géneros más estereotipados y con más pautas a seguir. Pero en un universo dominado por las fantasías masculinas como el del cómic más o menos de superhéroes, descuella este título, protagonizado por una heroína, que además no se origina de un sosías masculino (Supergirl, Batwoman). Sin duda, se trata de uno de los comic-books que más poder y preponderancia han otorgado a lo femenino, hasta el extremo que Hanegraaff lo considera feminista. ${ }^{62}$

\section{La comunidad misteriosa}

Como últimos títulos analizados en este artículo, se añadirán de manera más sumaria dos títulos menos célebres, aunque asimismo interesantes. Se comenzará por Strangehaven, un título muy innovador en cuanto a la dimensión creativo-industrial, puesto

58 Thierry Groensteen ya apunta a ese uso en otra serie de Alan Moore, Watchmen, aunque en ese caso se trate de splash pages y no spread pages, es decir, ocupen una página en lugar de las dos, pero se buscan por la misma razón del esplendor visual que ofrecen, si acaso multiplicado por dos en las extendidas a la doble hoja: Groensteen, T. Op. cit., p. 164.

59 Millidge, G. S. Op. cit., 233.

${ }^{60}$ Ibid., p. 237.

${ }^{61}$ Ibid., p. 232.

${ }^{62}$ Hanegraaff, W. J. (2016), Op. cit., pp. 235. Millidge considera de similar manera que el guionista construye personajes femeninos convincentes y fuertes, lo cual constituye una anomalía en un mundo tan masculino como el del cómic de superhéroes: Millidge, G. S. Op. cit., p. 301. 
que resulta la obra de una única persona, Gary Spencer Millidge, quien incluso auto-publicó los primeros números, con lo que lleva la independencia de los otros tres a un nivel mucho más extremo. Igualmente, Millidge ha escrito algunos ensayos sobre teoría del medio o ha analizado la trayectoria de Alan Moore, según se comentó más arriba.

En cuanto al diseño de página o al dibujo, resulta más convencional, en el sentido de que se trata de una obra mucho más clásica, con el panel dividido a menudo por las nueve viñetas de rigor. Eso sí, el estilo de dibujo resulta muy detallado, hiperrealista en la gestualidad, hasta el punto que se diría que parte de fotografías tanto en las figuras como en los espacios.

El lector sabe de la existencia del pueblo de Strangehaven, en el Reino Unido, pese a que no aparezca en los mapas, porque el protagonista del cómic ha tenido un accidente de coche y ha despertado allí. El protagonista intenta escapar del villorrio, pero no puede alejarse de él. Las carreteras secundarias de Strangehaven presentan un diseño laberíntico, que hace girar por ellas eternamente, dentro de un circuito circular, en banda de Möbius, cuyo destino final retorna a la entrada del pueblo.

Además, el extraño fenómeno no le acontece únicamente al protagonista: como descubrirá, la aldea se lo impide también a otros, como si poseyera voluntad propia, capacidad para hacerla cumplir y se sintiera celosa del resto de lugares del mundo. ${ }^{63} \mathrm{El}$ pueblo resulta un trasunto de Twin Peaks, tan misterioso como aquel de la teleserie, una especie de arquetipo de la comunidad rural británica. De hecho, destaca como uno de los ejemplos más claros de lo lyncheano en el cómic. ${ }^{64}$ Igual que en la serie, lo esotérico se filtra en la comunidad, crea una atmósfera enigmática que impregna el más banal de los gestos.

El pueblo permanece bajo el control de dos grupos espirituales, unos, trasuntos de la masonería, de la que se toma inspiración y en ocasiones copia tanto estructura de la orden como ritos y votos sagrados con fórmulas de juramento muy similares. En cuanto a los segundos, serían la versión Strangehaven de cierta New Age, brujas practicantes de wicca o un chamán educado como tal en el Amazonas, quienes intentan contrarrestar la magia de los primeros. Pero no dualísticamente, ya que, más que la eliminación del otro grupo, se pretende el equilibrio entre ambos, que se mantenga la relación.

El elenco de personajes recurrentes de Strangehaven resulta tan bizarro si no más que el de Trwin Peaks: para comenzar, una anciana que se comunica con los animales. O el

${ }_{63}$ Además de los loops espaciales, igual que en Promethea, también se experimentan temporales, a resultas del cual se unirá un matrimonio más de cincuenta años después de la muerte del marido.

${ }^{64}$ Valencia, J. J. Universo Twin Peaks. Alicante, Dilatando mentes, 2018, pp. 663-664. 
policía del pueblo, quien habla con su osito de peluche. Otro de los personajes insólitos del libro de cómic resulta ser un pretendido extraterrestre que lleva diecisiete años intentando ponerse en contacto con su especie.

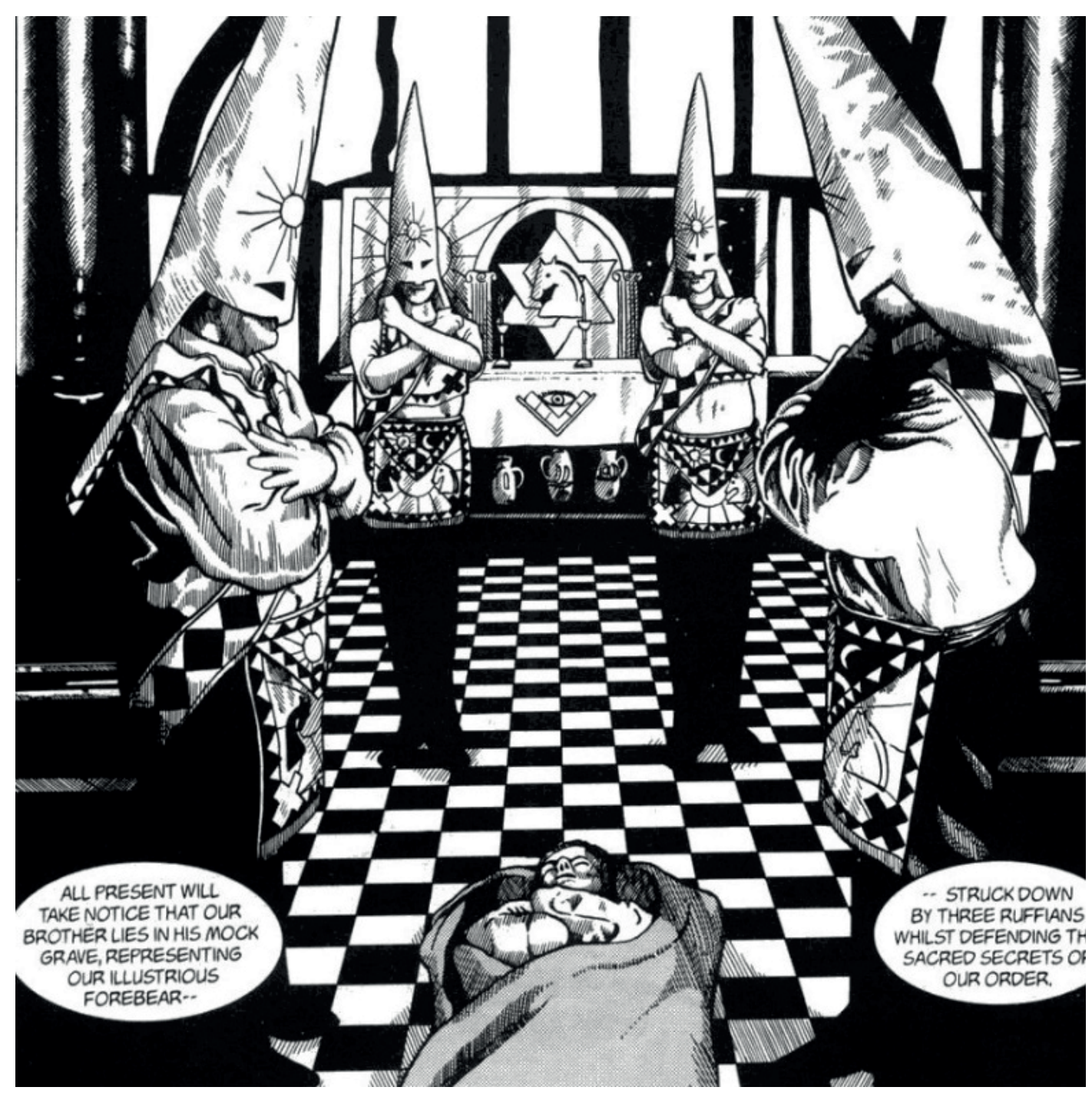

FIG. 7. Millidge, G. S. Strangehaven, vol. 1, n. ${ }^{\circ} 6$ (1997), p. 16. Primeros tres volúmenes autoeditados por el autor en Abiogenesis Press, la continuación ha sido publicada por Soaring Penguin Press.

Cortesía de Gary Spencer Millidge.

Debido a este personaje, el tema OVNI adquiere cierto peso en la narración, con explicaciones más o menos científicas sobre cómo funcionarían naves espaciales, o sociológicas para interpretar la mayoría de avistamientos. Y como no podía omitirse tratando 
este tema, se cita a Roswell. Precisamente la temática UFO ocupará el último título comentado en este artículo, por lo que, tras el influjo de Twin Peaks, tocará comentar una cabecera influida por otra serie de culto de resonancias ocultistas: Expediente $X$.

Saucer country, la obra en cuestión, fue editado en 2012 y 2013. Dentro de los temas del esoterismo en sentido amplio, expone uno que en las últimas décadas retorna periódicamente a la primera fila de este imaginario: las supuestas abducciones extraterrestres. Una gobernadora de los Estados Unidos que se presenta a las elecciones a la presidencia del país cree haberlo sido. Ha quedado traumatizada por ello ya que, entre otras acciones, puede haber sido violada. Sospecha que los extraterrestres desean conquistar las almas humanas para apoderarse del planeta, una conjetura muy querida por las teorías de la conspiración. En el cómic se describe bien la alt-right y los que promueven ese tipo de nociones de la sospecha en los medios. Se convierte en uno de los polos de tensión de la trama, con todos ellos, tanto los gubernamentales como la alt-right, jugando al gato y al ratón con los datos.

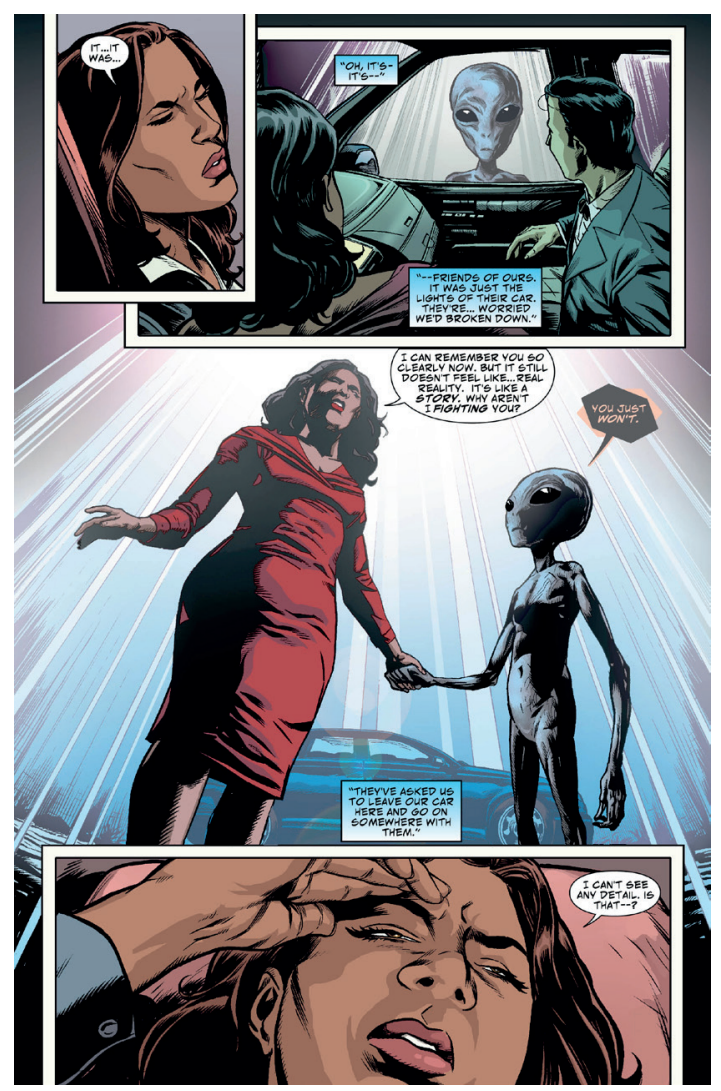

FIG. 8. Copyright (C) VERTIGO / DC COMICS. All rights reserved. CoRnell, P., y Kelly, R. Saucer Country, n. o 5 (2012), p. 7. Cortesía de Vertigo / DC Comics. 
Respecto al manejo de la información, resulta interesante uno de los personajes, profesor universitario, que se ha especializado en ufología y que, por ese motivo, pierde su empleo en la universidad. Para compensarlo, entra a trabajar como consejero de la candidata a presidente y protagonista de Saucer Country. Pero lo realmente peculiar de él radica en que recibe consejos de la pareja de humanos que fueron grabados en la placa de la nave Pioneer 10, con los que dar la bienvenida e información sobre la Tierra a posibles extraterrestres que interceptaran la nave.

El cómic enuncia la teoría sobre el paralelismo mitológico con las historias de hadas, las visiones de ángeles o similares. En un punto de vista ya expuesto por Jacques Vallée, Patrick Harpur o por Jeffrey Kripal, que pretende evitar conclusiones literales o taxativas, tanto una supuesta falsedad consubstancial de la experiencia - por ejemplo, como posible fuga psicótica-, pero al mismo tiempo sin conceder que se trate efectivamente de extraterrestres. Por tanto, dicha hipótesis huye de los sentidos literales. ${ }^{65}$ Se puede conjeturar que el autor del cómic ha leído a Vallée, Harpur o Kripal, pero a quien seguro que ha leído es a uno de los clásicos de la ufología, Charles Fort, de quien cita alguna de sus conjeturas.

Por último, cabe indicar que el divulgador de la occulture, Christopher Partridge, ha estudiado la cuestión de las abducciones. En un artículo en que analiza los nuevos movimientos religiosos que emplean mitología alienígena, el académico establece una influencia entre la teosofía y los extraterrestres con buenas intenciones respecto a los humanos, mientras que las raíces culturales de los aliens malvados, caso de algunos grises y de los reptilianos, se hallarían en la demonología judía y cristiana. ${ }^{66}$

\section{Conclusión: hechizo en las viñetas}

Para cerrar esta panorámica sobre los títulos fundamentales de los cómics de la occulture, se resumirán las principales ideas expuestas. Neil Gaiman o Alan Moore son alguno de los más grandes renovadores del género a partir de los años ochenta, tanto que algunos especialistas en este campo han considerado que gracias a ellos este medio artístico ha ganado respeto crítico. ${ }^{67}$

\footnotetext{
${ }^{65}$ Harpur, P. El fuego secreto de los filósofos. Vilaür, Atalanta, 2006, pp. 38-39. Kripal, J. Op. cit., pos. 5129 y ss. Probablemente el planteamiento de ambos parta de la forma en que entendió la cuestión C.G. Jung, en su Sobre cosas que se ven en el cielo, así como de Vallée en su Pasaporte a Magonia, quien ya analizaba los vínculos innegables de las abducciones con los raptos de los seres feéricos: VALLEE, J. Pasaporte a Magonia. Barcelona, Plaza \& Janes, 1972, pp. 42 y ss.

66 Partridge, C. «Alien demonology: the Christian roots of the malevolent extraterrestrial in UFO religions and abduction spiritualities», en Religion, 34, n. 3 (2004), pp. 163-189.

${ }^{67}$ Booker, Op. cit., pp. XXI-XXII.
} 
Pues bien, una de las características que mejor los define, tanto a ellos dos como a Grant Morrison, así como a los creadores de Strangehaven (Gary Spencer Millidge) y Saucer Country (Paul Cornell y Ryan Kelly), es compartir intereses por el esoterismo, una fascinación que otorga a sus obras de una atmósfera peculiar, así como de algunas ideas comunes. Se trata de artistas que consiguen transmitir en algunos de sus títulos cuan central, compleja y sofisticada puede resultar la exposición de lo oculto en el arte popular, con el cómic como difusor de ideas muy complejas entre públicos más amplios.

En el artículo se ha pretendido enumerar algunas de las pasarelas entre una cosmovisión ocultista y algunas obras. En The Sandman, Los invisibles, en la producción en general de Alan Moore, pero especialmente en su Promethea, en Strangehaven o en Saucer Country, lo esotérico aparece de una manera notoria, que colorea el universo expuesto con lineamientos provenientes de ese ámbito.

Entre otros temas predilectos del esoterismo europeo, en estos cómics se trata la creencia en seres no físicos o no terrestres - tanto imaginales como extraterrestres-, la simbología derivada de la cosmología ptolemaico-neoplatónica, el sistema por correspondencias, lo onírico y sus normas, y el recelo contracultural hacia el poder. Además, en los cómics comentados se citan a muchas de las figuras más destacadas del ocultismo, como Crowley o Hermes Trismegisto, y también aparecen citas y homenajes a obras de arte influidas por lo esotérico, como el enano de Twin Peaks.

Finalmente, se debe anotar que lo propuesto en este artículo ha sido obligatoriamente panorámico por necesidades de su formato, con lo que se ha ofrecido más una vista general que una explicación detallada de cada uno de los ejemplos. 


\section{BibLIOGRAFÍA}

Altarriba, A. «Características del relato en el cómic», en Neuróptica, n.o 1 (1983), pp. 9-38.

Asprem, E. Arguing with Angels. Enochian Magic E Modern Occulture. Albany, Sunny Press. State University of New York, 2012.

Barkun, M. A Culture of Conspiracy. Apocalyptic Visions in Contemporary America. Berkeley, University of California Press, 2003.

Beville, M. Gothic-postmodernism. Amsterdam, Rodopi, 2009.

Boокеr, M. K. «Preface», en Boокer, M. K. (ed.). Encyclopedia of Comic Books and Graphical Novels. Santa Barbara, Greenwood, 2010, pp. xxi-xxii.

Corbin, H. Cuerpo espiritual y Tierra celeste. Madrid, Siruela, 1996.

—El hombre de luz en el sufismo iranio. Madrid, Siruela, 2000.

Couliano, I. P. Experiencias del éxtasis. Barcelona, Paidós, 1994.

Dawson, L. L. «Anti-Modernism, Modernism, and Postmodernism: Struggling with the Cultural Significance of New Religious Movements», en Sociology of Religion, 59, n. ${ }^{\circ} 2$ (1999), pp. 131-156.

Faivre, A. «Introducción I», en Faivre, A. y Needleman, J. (eds.). Espiritualidad de los movimientos esotéricos modernos. Barcelona, Paidós, 2000, pp. 9-22.

Ferrer Ventosa, R. «Pensando en imágenes jeroglíficas», en Arte, individuo y Sociedad, 30, n. ${ }^{\circ} 2$ (2018), pp. 311-328.

Gilbert, R. A. «Hermetic Order of the Golden Dawn», en Hanegraaff, W. J. (ed.). Dictionary of Gnosis E Esotericism. Leiden - Boston, Brill, 2006, pp. 544-550.

Groensteen, T. Bande dessinée et narration. Paris, Presses Universitaires de France, 2011.

Grady, W. «Transcending the Frontier Myth: Dime Novel Narration and (Jesse) Custer's Last Stand in Preachern, en Pustz, M. (ed.). Comic Books and American Cultural History. New York, Continuum, 2012, pp. 40-58. 
Hanegraaff, W. J. New Age Religion and Western Culture. Leiden-New YorkKoln, Brill, 1996.

— «Alan Moore's Promethea: Countercultural Gnosis and the End of the World», en Gnosis. Journal of Gnostic Studies n. ${ }^{\circ} 1$ (2016), pp. 234-258.

Harpur, P. El fuego secreto de los filósofos. Vilaür, Atalanta, 2006.

Higgs, J. The K.L.F.: Chaos, Magic and the Band Who Burned a Million Pounds. London, Weidenfeld \& Nicolson, 2012.

Isabella, T. 1000 Comic Books You Must Read. Iola, Krause Publications, 2009 [e-book].

Koкkinen, N. «Occulture as an Analytical Tool in the Study of Art», en Aries n. ${ }^{\circ}$ 13 (2013), pp. 7-36.

Kraemer, C. H. y Winslade, J. L. ""The Magic Circus of the Mind”: Alan Moore's Promethea and the Transformation of Consciousness through Comics», en Lewis, A. D. \& Kraemer, C. H. (eds.). Graven Images: Religion in Comics and Graphic Novels. New York, Continuum, 2010, pp. 274-291.

Kripal, J. Mutants and Mystics: Science Fiction, Superhero Comics, and the Paranormal. Chicago, University of Chicago Press, 2015 [e-book].

Liagre, G. «Freemasonry and Protestantism», en Bogdan, H. \& Snoek, J.A.M. (eds.). Handbook of Freemasonry. Leiden / Boston, Brill, 2014, pp. 162-187.

Luttiknuizen, G. P. «The Demonic Demiurge in Gnostic Mythology», en Auffarth, C. y Stuckenbruck, L. T. (eds.). The Fall of the Angels. Leiden-Boston, Brill, 2004, pp. 148-160.

McCABE, J. Junto al rey del sueño: conversaciones con Neil Gaiman y sus colaboradores. Barcelona, Norma, 2007.

McCloud, S. Entender el cómic. El arte invisible. Bilbao, Astiberri, 2016 [2005].

Millidge, G. S. Alan Moore: storyteller. Barcelona, Planeta de Agostini, 2012.

Moore, A. Ángeles fósiles. Madrid, La Felguera, 2014.

Naranjo, F. Alan Moore: magia y precisión. Madrid, Sins Entido, 2004. 
Newman, W. \& Principe, L. Alchemy Tried in the Fire: Starkey, Boyle, and the Fate of Helmontian Chymistry. Chicago, University of Chicago Press, 2005.

Oviedo Salazar, M. «Reseña de Estudios sobre la historia del esoterismo occidental en América Latina», en Rehmlac+, vol. 9, n. ${ }^{\circ} 2$ (2018), pp. 288-295.

Palacios, J. Satán en Hollywood: una historia mágica del cine. Madrid, Valdemar, 1997.

Partridge, C. The Re-Enchantment of the West. Volume 1. London / New York, T\&T Clark International, 2004.

- The Re-Enchantment of the West. Volume 2. London / New York, T\&T Clark International, 2005.

- Alien demonology: the Christian roots of the malevolent extraterrestrial in UFO religions and abduction spiritualities», en Religion, 34, n. 33 (2004), pp. 163189.

Pasi, M. «Crowley, Aleister (born Edward Alexander)», en Hanegraaff, W. J. (ed.). Dictionary of Gnosis \&' Esotericism. Leiden - Boston, Brill, 2006, pp. 281-287.

Ramos Vera, M. «Más que superhéroes: filosofía del lenguaje, perennialismo y los cimientos de la realidad en Grant Morrison", en CuCo, Cuadernos de cómic n. 15 (2020), pp. 52-70. Disponible en http://cuadernosdecomic.com/docs/revista15/3\%20M\%C3\%A1s\%20que\%20superh\%C3\%A9roes\%20-\%20Mario\%20 Ramos.pdf

Rhoades, S. A Complete History of American Comic Books. Nueva York, Peter Lang Publishing, 2008.

Ross, D. «La amenaza de lo fantástico», en Roas, D. (comp). Teorías de lo fantástico. Madrid, Arco / Libros, 2001, pp. 7-46.

Round, J. Gothic in Comics and Graphic Novels. Jefferson, McFarland \& Company, 2014.

Szonyı, G. E. John Dee's Occultism. Magical Exaltation through Powerful Signs. Albany, State University of New York Press, 2004.

Ursini, F., Mahmutovic, A. y Bramlett, F. «Which Side Are You On? The Worlds of Grant Morrison». Conference Paper, [sin más datos], 2014. Disponible 
en https://www.researchgate.net/publication/314875769 Which side are you on The worlds of Grant Morrison [último acceso 11/12/2020].

Valencia, J. J. Universo Twin Peaks. Alicante, Dilatando mentes, 2018.

VAllée, J. Pasaporte a Magonia. Barcelona, Plaza \& Janes, 1972.

Weber, M. Sociología de la religión. Madrid, Itsmo, 1997.

YAtes, F. A. Giordano Bruno y la tradición hermética. Barcelona, Ariel, 1983. 